\title{
Dualidades nas propostas editoriais de música antiga brasileira
}

\author{
Paulo Castagna (UNESP) \\ brsp@uol.com.br
}

Resumo. A partir da primeira publicação de caráter musicológico de música brasileira do século XVIII, realizada em 1951 por Francisco Curt Lange (Archivo de Música Religiosa de la "Capitania Geral das Minas Gerais"), surgiram iniciativas brasileiras que manifestaram as mais variadas propostas editoriais. 0 estudo das edições produzidas no país nas últimas cinco décadas revela várias dualidades, dentre as quais as dez mais importantes serão abordadas neste artigo: 1) publicação ou circulação informal; 2) Gesamtausgaben ou Denkmähler; 3) edição acadêmica ou edição prática; 4) fontes de um único acervo ou de vários; 5) obra isolada ou coletânea; 6) trabalho individual ou trabalho de equipe; 7) obras inéditas ou já divulgadas; 8) financiamento privado ou de instituições governamentais; 9) apenas partitura ou partituras e partes; 10) divulgação em papel ou em meios eletrônicos. Além da identificação dessas dualidades, o objetivo deste artigo é tentar compreender o seu significado e relacioná-las às atuais perspectivas editoriais da música antiga no país.

Palavras-chave: música antiga brasileira; edição musical; dualidades editoriais.

\section{Editorial propositions's dichotomies in Brazilian early music}

Abstract. Departing from the first musicological publication about eighteenth-century Brazilian music by Francisco Curt Lange in 1951 (Archivo de Música Religiosa de la "Capitania Geral das Minas Gerais"), other initiatives appeared in Brazil manifesting a wide range of editorial solutions. The study of the editions produced in this country in the last five decades reveals several dichotomies, ten of the most important being: 1) published work or informal circulation; 2) Gesamtausgaben or Denkmähler; 3) academic edition or interpretive edition; 4) sources from one or several collections; 5) isolated work or collective works; 6) individual work or team-work; 7) unpublished works or previously published works; 8) private funding or governmental funding; 9) scores only or scores and parts; 10) paper or digital/electronic publishing. Besides the identification of those dichotomies, the objective of this paper is to understand their meanings and relate them to the current editorial perspectives of early music in Brazil.

Keywords: Brazilian early music; music edition; publishing dichotomies.

\section{1 - Introdução}

No Brasil imprimiu-se música apenas a partir da década de 1830, muito depois, portanto, de regiões hispanoamericanas, como México, Peru, Chile e outras, onde já se publicava música nos séculos XVI, XVII e XVIII. Na segunda metade do século XIX e primeira metade do século XX houve uma razoável produção editorial, especialmente em torno de editores estrangeiros estabelecidos no Brasil, porém na segunda metade do século XX esse tipo de atividade começou a entrar em declínio, como um reflexo do próprio declínio da música executada por meio de partituras.

A edição de música antiga brasileira, no país, iniciou-se justamente quando as editoras diminuiam drasticamente sua oferta, passando a imprimir preferencialmente o tipo de música mais vendável e com o menor custo de produção, como métodos didáticos e arranjos, especialmente de música popular, para os instrumentos mais tocados, como piano, violão, guitarra, bateria e outros. 0 resultado é que a imensa maioria das edições de música antiga brasileira tem sido impressa por instituições acadêmicas, governamentais ou fundações que, em sua origem, não previam esse tipo de atividade.

Neste trabalho abordaremos alguns aspectos históricos referentes à edição de música antiga brasileira no Brasil, o que gera uma redundância inevitável na definição do objeto, mas que tentará ser minimizada nas próximas referências ao mesmo. Considerando-se, aqui, a edição não somente como a publicação de uma determinada obra, mas enquanto a atividade que leva ao estabelecimento do texto musical de uma determinada composição, seja ela divulgada em forma manuscrita, por fotocópias, por edições em computador ou por edições eletrônicas, disponíveis na internet ou apenas transmitidas eletronicamente aos interessados pelos respectivos editores (FIGUEIREDO, 2000). 


\section{2- Edições brasileiras de música antiga}

Embora tenham existido edições precursoras desse repertório desde o final do século XIX, com destaque para a impressão do Requiem e da Missa em si bemol de José Maurício Nunes Garcia pela Casa Bevillacqua em 1897,' foi o Archivo de Música Religiosa de la "Capitania Geral das Minas Gerais", com a edição de três obras mineiras por Francisco Curt Lange, impresso em 1951 pela Universidad Nacional de Cuyo (Argentina), que desencadeou uma nova abordagem em relação a esse repertório, ou seja, a edição com finalidades musicológicas, apesar de todas as limitações que tiveram esta e as publicações posteriores.

Após o estímulo de Curt Lange, as primeiras edições brasileiras surgiram quase sempre isoladas em apêndices de livros, como é o caso das publicações de Geraldo Dutra de MORAES (1975), Curt Lange (LOBO DE MESOUITA, 1979) e Maria da Conceição Rezende Fonseca (LOBO DE MESOUITA, 1985), ou em artigos de periódicos, como no caso de Régis DUPRAT (1971 e 1986), sendo importantes precursores os suplementos musicais dos periódicos Música Sacra (Petrópolis: Vozes, 1941-1959) e Revista Brasileira de Música (Rio de Janeiro: Instituto Nacional de Música, 1934-1944). Esse tipo de opção editorial continua a ser adotado até o presente, acrescentandose ao mesmo as edições como anexos de trabalhos ou comunicações em eventos, dissertações de mestrado e teses de doutorado, cada vez mais freqüentes. Em menor quantidade, naquela fase, estavam os volumes dedicados a uma única composição, como os trabalhos de Régis DUPRAT (GOMES, 1966) e Jaime DINIZ (PINTO, 1968; ARAÚJ0, 1970). Posteriormente agregaram-se a essas as coletâneas ou antologias, para as quais podemos citar, entre outras, como importantes precursoras as de Pedro SINZIG (1921), Mário de ANDRADE (1930), João Baptista SIQUEIRA (1956) e Mozart de ARAÚJO (1963).

Foram, entretanto, as séries editoriais as que mais contribuíram do ponto de vista quantitativo e qualitativo para o desenvolvimento desse tipo de atividade no Brasil. A primeira delas foi a coleção Música Sacra Mineira, publicada pela Funarte no final da década de 1970, que resultou em 77 obras avulsas. ${ }^{2}$ Em tal série foi utilizada uma metodologia empírica, baseada mais na prática musical que em critérios musicológicos e com uma excessiva atribuição a determinados compositores de obras sem indicação de autoria. As fontes utilizadas para as edições foram principalmente aquelas localizadas e micro-filmadas pelo projeto 0 ciclo do ouro, em acervos de São João del-Rei, Prados, Tiradentes, Mariana e Diamantina, selecionando-se geralmente uma fonte de cada composição. Sua circulação foi bastante restrita e os exemplares esgotaram-se justamente no período em que a musicologia começou a manifestar um maior desenvolvimento no país. Mesmo assim, essa coleção teve um grande significado na musicologia brasileira, não somente pela quantidade de títulos impressos, mas pela difusão da própria perspectiva editorial. A coleção Música Sacra Mineira, ao lado das edições anteriores das décadas de 1960 e 1970, foi uma das grandes responsáveis pela possibilidade de uma musicologia baseada no estudo de obras musicais, perspectiva diferente da tendência que predominou na musicologia brasileira até a década de 1960, que era o estudo dos autores, quase sempre de caráter predominantemente biográfico.

Devido ao seu significado, mas também à descontinuidade da pesquisa que a gerou, a coleção Música Sacra Mineira foi reimpressa várias vezes, embora em nenhuma delas de forma integral. Em 1997 José Maria Neves organizou os títulos impressos, publicou seu catálogo e coordenou a reimpressão de 12 das 77 obras, agora com alguns critérios musicológicos, como a indicação das fontes utilizadas e sua revisão. Essas 12 obras foram reimpressas novamente em 2000 e 2002, dessa última vez como parte do sexto volume da série Música no Brasil - séculos XVIII e XIX, também da Funarte, com uma nova revisão, porém sem outras novidades de caráter musicológico.

A série que efetivamente introduziu as edições de caráter musicológico no Brasil foi aquela dedicada às obras de José Maurício Nunes Garcia, impressas em 9 volumes pela Funarte, entre 1978 e 1984 . Em tal série, a editora Cleofe Person de Mattos apresentava, além da partitura, uma discussão sobre suas fontes, acompanhadas de facsímiles, além da indicação das correções efetuadas. Do ponto de vista metodológico, nenhuma outra série, até o final da década de 1990, apresentou avanços em relação às edições de Cleofe Person de Mattos e quase nenhuma incorporou integralmente sua proposta musicológica.

Três séries editoriais foram ainda lançadas na década de 1990, duas delas pela Editora da Universidade de São Paulo: as coleções Música do Brasil Colonial (a partir de 1994), com 4 volumes até o momento, e Música Brasileira, (a partir de 1999), até agora com 2 volumes dedicados à música sacra antiga e 2 ao repertório romântico. A essas duas somou-se a série de 3 volumes impressa pelo Editorial Baluarte [1995], com obras mineiras e cariocas. Tais séries adotaram principalmente o critério da edição prática, dando pouca ênfase à indicação de correções (mais largamente utilizadas no primeiro volume da coleção Música Brasileira) ou à localização de fontes das composições impressas. Em geral, tais séries utilizaram uma fonte por composição, priorizando aquelas originárias do acervo no qual trabalhavam seus editores.

Por outro lado, as séries da década de 1990 tiveram um significado especial, pois esse foi um período de grande transformação da musicologia brasileira, na qual os modelos positivistas, baseados em compilações ou descrições e focados em autores e obras, começou a ser substituído por uma pesquisa interpretativa e mais interessada no significado dos fenômenos observados. Nessa época as edições entraram em declínio, sendo cada vez mais consideradas uma atividade mecânica e ultrapassada, frente à visão analítica e interpretativa da Nova Musicologia. Por isso, as três séries editoriais 
iniciadas na década de 1990, duas delas com títulos ainda sendo lançados pela Editora da Universidade de São Paulo, representaram uma importante resistência à extinção da atividade editorial e um grande estímulo ao surgimento das séries da década seguinte.

A primeira década do século XX parece representar um ressurgimento da atividade editorial, com o lançamento, em menos de cinco anos, de uma quantidade de obras maior que todas as impressas nas décadas de 1980 e 1990 juntas. A primeira série dessa fase foi Acervo da Música Brasileira / Restauração e Difusão de Partituras (Fundarq, Petrobras e Santa Rosa Bureau Cultural, 2002-2003), que lançou 9 volumes de partituras e de Cds, com a gravação de todas as obras impressas. Tal série apresentou vários avanços, como a localização e consideração do maior número possível de fontes para cada obra, a elaboração de um aparato crítico com a indicação precisa das alterações realizadas, maior atenção ao significado litúrgico das obras, um sistema de revisão mais preciso, o lançamento simultâneo de edições e gravações das mesmas obras e a disponibilização gratuita das partituras e das fontes manuscritas na internet. Por outro lado, essa série teve sérias limitações, entre elas a não impressão das partes vocais e instrumentais ${ }^{3}$ e a utilização quase exclusiva de manuscritos do Museu da Música de Mariana, condição apresentada pelas instituições envolvidas no projeto.

Quase simultaneamente à série mineira, a Funarte lançou em 2002 os 6 volumes da série Música no Brasil - séculos $X V I I I$ e $X I X$, um dos quais destinados à quarta reimpressão da série Música do Brasil Colonial, como vimos. Essa nova série da Funarte lançou importantes títulos, cuja própria existência causou impacto positivo no meio musicológico, destacando-se as de Sigismund Neukomm e Luís Álvares Pinto. Na mesma época (2002), a editora Criadores do Brasil, da Orquestra Sinfônica do Estado de São Paulo, lançou uma série que já conta com 45 composições avulsas do repertório erudito brasileiro dos séculos XVIII a $X X$, entre elas algumas importantes obras antigas. $A$ série Ouro de Minas, da Editora Pontes, surgiu em 2005, com o objetivo de editar apenas música mineira, tendo já lançado 20 títulos, além de uma coletânea em um volume. Essas três séries utilizaram a mesma metodologia da década de 1990, nem sempre mencionando as fontes utilizadas e com pouca ênfase na explicitação das interferências musicológicas, mas com um significativo impacto quantitativo na produção editorial brasileira. ${ }^{4}$

Paralelamente às séries editoriais, várias outras coletâneas ou volumes dedicados a uma única obra foram lançados desde a década de 1980, com destaque para Te Deum em ré maior, atribuído a Manoel Dias de OLIVEIRA (1989), Música sacra paulista (DUPRAT, 1999), a nova edição do Recitativo e ária para José Mascarenhas (DUPRAT; VOLPE; TONI, 2000), As modinhas do Brasil (LIMA, 2001), Cifras de música para saltério (SANTOS, 2002) - uma extraordinária coleção de música instrumental de salão da primeira metade do século XIX, decifrada e impressa por Rogério Budasz - e Lobo de Mesquita no Museu da Música de Mariana (COTTA, 2005). As próprias datas de impressão desses trabalhos demonstram o quanto a atividade editorial vem crescendo a partir da transição do século XX para o XXI.

Outros volumes e séries editoriais estão em preparação, o que parece confirmar a tendência de ressurgimento da edição no Brasil enquanto atividade musicológica, entre elas a série Patrimônio Arquivistico-Musical Mineiro, a ser lançada no início de 2008, que utiliza a metodologia desenvolvida na série Acervo da Música Brasileira, porém acrescenta a publicação das partes, inclusive na internet, e realiza um levantamento amplo de fontes das obras impressas, a partir da pesquisa em cerca de 15 acervos diferentes.

\section{3- Dualidades}

Além dos aspectos históricos referentes às edições brasileiras de música antiga, entre as quais destacamos seu surgimento em um período de decadência generalizada da atividade editorial e a própria decadência das edições enquanto atividade musicológica, esta última possivelmente em reversão na atualidade, observa-se, nas mesmas, interessantes dualidades de propostas, ou seja, extremos opostos no que se refere aos métodos, critérios, recursos, objetivos, abordagens, formas de apresentação e outros aspectos do trabalho editorial. Esses extremos representam posições adotadas pelos editores e, às vezes, pelas instituições envolvidas nas edições, os quais defendem os princípios adotados como os mais adequados e tendem a repeti-los a cada novo trabalho, nem sempre os submetendo à crítica ou refletindo sobre o seu significado. Destacamos dez dentre esses dualismos para discussão.

\section{1 - Publicação ou circulação informal}

Uma parte dos editores somente faz circular suas edições após sua publicação, enquanto outra parte dá preferência à circulação de edições não impressas. Em geral, os primeiros estão mais ligados à musicologia histórica e os outros à vertente da "performing practice" ou mesmo à prática musical, sem muitas ligações com a atividade musicológica ou acadêmica. É muito difícil encontrar um editor que pratique igualmente as duas modalidades de difusão, geralmente encontrando-se as posições opostas. Muitas vezes grandes editores, com significativa produção musicológica, dão total preferência à circulação para execução e gravação de edições não impressas, sendo Bernardo Illari um notório exemplo internacional.

Publicar ou não as edições depende da necessidade desse recurso. Às vezes o resultado do trabalho não agrada nem seus editores, nem seus financiadores, nem os conjuntos musicais e nem o público, não havendo muitas razões para sua publicação. 0 maior problema, no entanto, são as obras que despertam interesse público e cujas edições, quando existem, circulam informalmente, sendo difícil ou às vezes quase impossível localizá-las. Exemplo clássico é o de Francisco Curt Lange, falecido em 1997, e cujas edições circulam em sua maior parte informalmente, uma 
vez que este fez imprimir apenas quatro obras, dentre as várias que editou: seus trabalhos editoriais não impressos podem ser encontrados em algumas instituições, como Biblioteca Nacional do Rio de Janeiro, a Biblioteca da Universidade Federal de Minas Gerais e outras, porém a obtenção de uma cópia pode demandar tanto tempo e esforço que uma nova edição, a partir das fontes primárias, às vezes parece ser uma solução mais fácil.

Ligada a esse assunto, outra questão que surge no meio musicológico é se a existência de uma edição, mesmo que nunca antes publicada, admite ou não a possibilidade de uma nova edição. Se a resposta a essa pergunta fosse negativa, teríamos de assumir que toda e qualquer edição de uma obra seria definitiva, não sendo cabíveis novas propostas editoriais, a consulta de fontes da mesma obra antes desconhecidas, a consideração de aspectos não incluídos na edição mais antiga, etc. Imagine-se, por exemplo, o caso de Giovanni Pierluigi da PALESTRINA (c.1525-1594): seria possivel realizar novas edições de suas obras ou deveríamos sempre nos contentar com as edições de Franz Xaver Haberl e Franz Espagne, impressas entre cerca de 1870 e 1907? Pelo contrário, de acordo com o moderno conceito de edição, não existe a idéia de uma edição definitiva (GRIER, 1996). Mas é sempre preciso saber, ao se reeditar uma obra que dispõe de uma ou mais edições anteriores, se esse novo trabalho é realmente necessário, se irá mudar a visão que se tem da obra ou se o que está em jogo é apenas a competição entre editores. ${ }^{5}$

\section{2 - Gesamtausgaben ou Denkmähler}

Gesamtausgaben e Denkmähler são conceitos de origem alemã e representam, respectivamente, as séries ou coletâneas dedicadas às obras completas de um determinado autor e às obras de um determinado país ou região. Em latim são usadas as expressões equivalentes "opera omnia" e "monumenta", também aparecendo, em português, com os nomes de "obras completas" e "monumentos", embora nem sempre o grau de completude seja atingido.

Em seus primórdios, a edição de música antiga, já após a fundação da Bach Gesellschaft em 1850, privilegiou as Gesamtausgaben, de autores como Bach e Palestrina, depois Beethoven, Lassus, Mozart, Schubert, Schumann, Schütz, Victoria e outros. Por outro lado, inúmeras séries européias lançadas no século XX eram Denkmähler, como a conhecida Portugaliæ Musica, da Fundação Calouste Gulbenkian. A própria idéia de uma Monumenta Musicæ Brasiliæ, de Francisco Curt Lange, que nunca saiu do primeiro volume impresso na Argentina em 1951, era, essencialmente, a de uma Denkmahl.

É preciso reconhecer que, em sua origem, esses dois conceitos carregam um forte conteúdo ideológico: as antigas Gesamtausgaben européias, além de tentar elaborar utópicas edições "definitivas", privilegiavam os compositores "importantes", enquanto as Denkmähler, por todo o mundo, basearam-se em um inegável espirito nacionalista, publicando grandes quantidades de música nacional, nem sempre importando sua qualidade ou representatividade.

0 próprio surgimento das edições brasileiras de música antiga foi marcado por esse dualismo: as duas primeiras séries da Funarte foram a coleção Música Sacra Mineira e as obras de José Maurício Nunes Garcia, respectivamente Denkmahle Gesamtausgabe. Afora o caso de Cleofe Person de Mattos, musicólogos como Francisco Curt Lange, Régis Duprat e Jaime Diniz, para citar apenas os mais antigos, manifestaram tendência às Gesamtausgaben, priorizando a edição de música respectivamente de José Joaquim Emerico Lobo de Mesquita, André da Silva Gomes e Luis Álvares Pinto, enquanto um outro grupo de editores deu preferência às Denkmähler, editando conjuntos de obras originárias dos estados de Minas Gerais, São Paulo, Maranhão, Pernambuco e outros.

Curiosamente, as Denkmähler brasileiras estiveram e talvez ainda estejam mais preocupadas com a divulgação de música de Estados específicos que do Brasil como um todo, revelando certa competição regionalista entre elas ou entre seus musicólogos. A já histórica coleção Música Sacra Mineira, além de imprimir obras escritas em Minas Gerais, deu evidente destaque a compositores da região do Campo das Vertentes, justamente onde viviam seus editores.

Talvez a questão mais importante a ser feita hoje, antes de se buscar novas perspectivas editoriais, é tentar determinar o que vale a pena ser publicado. Sabendose que a impressão de música sempre envolve esforços e recursos, muitas vezes escassos, é preciso estabelecer prioridades editoriais, antes de se optar por tendências tão marcadamente ideológicas como essas.

\section{3 - Edição acadêmica ou edição prática}

A edição acadêmica é a edição de caráter musicológico, destinada inicialmente a um maior conhecimento da obra e, somente de forma secundária, à sua execução. Nesse tipo de edição dá-se destaque à situação das fontes manuscritas, à refutação das versões transmitidas em forma impressa, quando é o caso, e à explicitação dos critérios e interferências editoriais, entre outros aspectos, havendo vários tipos de edições conforme sua utilidade e conveniência (edição critica, edição aberta, edição facsimilar, edição diplomática, edição genética, etc.). A edição prática, por outro lado, é aquela essencialmente destinada à execução da obra e que incorpora indicações e instruções de natureza interpretativa, de acordo com as opiniões de seus editores, que em geral são especialistas nos instrumentos ou conjuntos para os quais a obra está destinada.

Também denominada interpretativa, por alguns autores, as edições práticas nem sempre têm suas propostas compreendidas pelos músicos, editores e musicólogos, que, muitas vezes as tratam como um gênero menor e decorrente da rápida transcrição de uma determinada fonte, sem a necessidade de consulta das demais fontes 
conhecidas. Uma boa edição prática, no entanto, pode ser feita a partir de uma edição acadêmica e preocupar-se somente com as questões interpretativas, incluindo os aspectos com os quais nem sempre os editores-musicólogos estão preparados para lidar, tais como dinâmica, agógica, fraseado, articulação, arcadas, andamento, realização de cifras e ornamentos, etc.

As edições brasileiras de música antiga em geral têm se colocado em extremos opostos em relação a esses aspectos, sendo raras as edições que contemplem simultaneamente interesses musicais e musicológicos, mas é fácil perceber que, até a transição do século XX para o XXI, predominaram as edições práticas, surgindo nessa época as edições acadêmicas, destinadas principalmente aos musicólogos.

Também aqui é preciso considerar a aplicação de uma ou outra possibilidade e também admitir a possibilidade de soluções intermediárias, uma vez que nem sempre é possivel optar-se por uma edição exclusivamente prática ou acadêmica. As edições ecléticas, por exemplo, que os críticos textuais também denominam ecléticas racionais, nas quais é confrontada a música do maior número possivel de fontes, obtendo-se uma versão que as considera simultaneamente, muitas vezes é utópica para o caso brasileiro, uma vez que é possivel localizar dezenas de cópias diferentes de uma mesma composição, tornando bastante difícil optar-se por uma única variante dentre as muitas encontradas para cada passagem da peça (ou "lição", como preferem os críticos textuais). Do Credo de Jerônimo de Sousa (fl.1746-1826), por exemplo, são conhecidas mais de 50 cópias em acervos mineiros e paulistas, o que torna a edição eclética uma tarefa particularmente difícil neste caso. Aqui, portanto, é mais viável, para o adepto da edição acadêmica, a utilização de uma quantidade menor de fontes do que nenhuma edição, sob a justificativa de que a consulta de todas as fontes seria quase impossivel.

\section{4 - Fontes de um único acervo ou de vários}

À exceção das edições de Cleofe Person de Mattos, as demais séries impressas no século $X X$ não deram muita atenção à diferença entre as fontes e não realizaram 0 levantamento das distintas fontes de uma mesma obra em vários acervos, tendência que começou a ser observada somente em séries impressas na primeira década do século XXI. Predominou, portanto, a utilização de fontes de acervos nos quais trabalhavam ou pesquisavam seus editores, embora já existam edições e projetos que partem de uma consulta ampla às fontes conhecidas.

Essa polarização causa vários efeitos prejudiciais à atividade editorial. 0 primeiro deles, relacionado à discussão do item anterior, é a edição de apenas uma determinada variante de uma obra, às vezes diferente daquela encontrada em fontes mais antigas ou até em autógrafos existentes em acervos diferentes daqueles que serviram de base para os editores. A necessidade de consultar todas as fontes de uma determinada obra, por outro lado, retarda as edições, tornando-as por vezes utópicas, nem sempre possíveis de serem concretizadas. Em Minas Gerais, por exemplo, onde existem cerca de quinze acervos de grande porte mais ou menos conhecidos, porém dezenas ou talvez centenas de acervos de pequeno e médio porte pertencentes a corporações de música, instituições administrativas, religiosas e de ensino, cujo conteúdo ainda não foi investigado do ponto de vista musicológico, é quase inviável tentar-se consultar todas as fontes de uma determinada obra para sua edição.

0 segundo efeito prejudicial é a possibilidade de surgimento de "feudos" em torno de acervos, ou seja, grupos de pesquisadores ou iniciativas editoriais que fecham-se em torno de um determinado arquivo ou coleção, desconhecendo ou não considerando fontes externas e, às vezes, dificultando o trabalho de outros interessados nesse mesmo acervo.

Por essas razões, um projeto editorial precisa pesar com cuidado as implicações de cada uma dessas situações extremas e, sempre que possivel, optar por uma solução intermediária, em lugar de desconsiderá-las como ponto de partida.

\section{5 - Obra isolada ou coletânea}

As edições de música antiga brasileira começaram enfatizando a publicação de obras isoladas, porém a partir da década de 1990 a ênfase recaiu sobre as coletâneas, ou seja, publicações com várias obras, muitas vezes de distintos autores e temas. Assim como a edição de coletâneas, com algumas exceções, parecia estranha no Brasil nas décadas de 1960 a 1980, a edição de obras isoladas, atualmente, parece ser um desperdício ou até mesmo uma impossibilidade, se levarmos em consideração as dificuldades comerciais de sua divulgação.

A coleção Música Sacra Mineira, na década de 1970, foi uma manifestação extrema do primeiro caso: além de publicar isoladamente as composições, algumas foram subdivididas em obras menores, como certas Matinas, Setenários, Novenas e conjuntos de Motetos de Passos, cujos Invitatórios, Responsórios, Antífonas e Motetos foram impressos separadamente, como obras distintas. Por isso, a coleção foi em seguida reorganizada e as distintas unidades musicais pertencentes a uma mesma unidade cerimonial foram reunidas em uma mesma publicação, aparecendo finalmente juntas todas as unidades de Novenas, Matinas, etc. Caso interessante foi o das Matinas do Natal de João de Deus de CASTRO LOBO (s.d.), da qual somente o Invitatório foi publicado, não ocorrendo o mesmo com os oito Responsórios, ou seja, com a maior parte da composição.

Talvez a questão que mais tenha tocado os editores na década de 1990 e os movido em direção às coletâneas tenha sido a necessidade de publicar maior quantidade de obras, uma vez que novas peças iam sendo cada vez 
mais conhecidas e necessitavam ser divulgadas. Por outro lado, as coletâneas que surgiram nessa fase nem sempre apresentavam uma temática em torno da qual as peças estavam reunidas, questão que começou a ser refletida somente na transição do século XX para o XXI.

Atualmente, as coletâneas temáticas convivem com a edição de obras isoladas, sendo mais fácil optar-se por uma ou outra possibilidade. Para esta categoria, pelo menos, não estamos tão presos à tradição, como em outros casos, sendo a decisão por uma ou outra categoria dependente apenas dos propósitos do projeto editorial.

\section{6 - Trabalho individual ou trabalho de equipe}

Essas duas polaridades são observadas desde o início das edições brasileiras de música antiga e carregam significados distintos. 0 trabalho individual, por um lado, é mais livre e possibilita maior especialização ou aprofundamento em certos aspectos editoriais ou do repertório editado, mas por outro, as limitações ou deficiências do editor não podem ser sanadas a partir de um único ponto de vista e tornam-se evidentes no resultado. 0 trabalho em equipe, no entanto, permite corrigir as falhas de cada editor e unir diferentes pontos de vista, mas cria maior lentidão no processo editorial $e_{1}$ às vezes, divergências de opinião, que precisam ser administradas.

É certo que o trabalho individual em musicologia é historicamente mais antigo e o trabalho em equipe mais recente, mas isso não significa que o trabalho em equipe seja a única possibilidade válida. Certas pessoas, por sua natureza, produzem melhor individualmente, enquanto outras são mais aptas ao trabalho em equipe, e isso não é uma questão política ou acadêmica, mas uma tendência natural do ser humano. Creio que a questão principal é saber exatamente quando se deve optar pelo trabalho individual ou pelo trabalho de equipe, levando-se em consideração as necessidades do projeto editorial, em lugar de defender, a priori, uma ou outra possibilidade como a melhor.

\section{7 - Obras inéditas ou já divulgadas}

Essa questão tem origem antiga. As editoras comerciais em geral privilegiam obras já conhecidas e, muitas vezes, já impressas, pois para elas a vendagem sempre está acima de qualquer interesse acadêmico ou ideológico. Por outro lado, no meio musicológico sempre houve total predileção pelas obras "inéditas", surgindo, por essa razão, várias definições do que seria uma composição inédita: obra ou versão nunca antes impressa (ou nunca antes totalmente impressa), obra ou versão nunca antes executada ou gravada, etc.

0 grande problema dessa questão, sobretudo no meio musicológico, é que o trabalho editorial, muitas vezes, é julgado mais pelo ineditismo das obras impressas do que por quaisquer outros parâmetros, o que desestimula a edição de peças que já tenham sido anteriormente publicadas, mesmo que por critérios não mais atuais, esgotadas e dificeis de serem localizadas.

É preciso reconhecer que existe uma clara função para cada uma dessas possibilidades e que a opção por apenas uma, como perspectiva de trabalho, causa certos prejuízos. A edição de obras inéditas é obviamente útil para colocar em circulação peças antes desconhecidas ou conhecidas apenas nos círculos musicológicos, mas a reedição de peças anteriormente impressas permite a utilização de novos critérios e novas fontes, a valorização de novos aspectos e a obtenção de novos resultados, como já discutimos anteriormente.

Talvez a exclusiva opção pelo ineditismo tenha levado certos musicólogos a não reconhecer a importância acadêmica da reedição, opondo-se a novos trabalhos com obras das quais já existiam edições anteriores. Essa postura, nitidamente marcada pela idéia da edição "definitiva", dificulta o desenvolvimento da edição enquanto atividade acadêmica e inviabiliza novos conhecimentos sobre o repertório já impresso. Sobre essa questão, é preciso lembrar que o próprio surgimento do conceito de "edição crítica" parte da rejeição à edição anterior de uma determinada obra como verdade única, para retornar às fontes e propor novas soluções editoriais (GRIER, 1996).

Assim, no caso brasileiro, um exemplo marcante está novamente na coleção Música Sacra Mineira, cujos exemplares são difíceis de serem encontrados, mesmo em bibliotecas. Justamente por isso, a própria Funarte financiou três reedições do um grupo de 12 das 77 obras impressas na década de 1970, como vimos anteriormente (NEVES, 1997). Embora louváveis, essas reedições deixaram de fora a maior parte das obras, cuja reedição seria importante, mesmo que facsimilar, em função da pequena tiragem que tiveram na primeira edição. Além disso, os métodos e critérios utilizados na coleção Música Sacra Mineira, que hoje não satisfazem nem as necessidades musicais e nem as acadêmicas, justificam plenamente novas edições das mesmas obras, inclusive daquelas reimpressas pela Funarte, pois as reedições corrigiram muitos problemas musicais, mas não avançaram muito em aspectos propriamente musicológicos.

\section{8 - Financiamento privado ou de instituições governamentais}

Considerando-se o período no qual as edições de música antiga surgiram no Brasil, com a quase total ausência de publicações realizadas por editoras comerciais, foi maciça a opção pelas edições financiadas, inicialmente por organismos governamentais, incluindo-se aí as universidades, museus e agências federais ou estaduais de apoio à cultura. Obviamente, na maior parte dos casos não houve outra opção, mas o grande problema, aqui, foi a freqüente desconsideração de outras possibilidades. 
Se, nas últimas quatro décadas do século $X X$ financiamento oficial foi a regra, a situação começou a mudar no início do século XXI, com o surgimento de iniciativas apoiadas por empresas privadas e fundações, acelerando a produção editorial brasileira e criando novas opções para uma atividade que foi tão restrita no século XX.

Mas, novamente, precisamos compreender o significado de cada opção. Quando qualquer instituição financia um projeto editorial, não o faz apenas por filantropia, mas principalmente como uma forma de propaganda. Não existe o patrocínio da arte apenas por amor à arte, assim como não foram enviados foguetes à Lua apenas por amor à ciência. Desde o Renascimento, os príncipes que financiavam a produção artística tinham em mente a propaganda de seu poder e do seu status, antes mesmo das questões propriamente artísticas.

Assim, ao se propor ou aceitar um projeto editorial financiado, é preciso estar ciente de qual instituição estará sendo beneficiada com o produto final e por qual razão, sob o risco de se expor o trabalho profissional a qualquer tipo de exploração política.

\section{9 - Apenas partitura ou partituras e partes} A grande maioria das edições brasileiras de música antiga, até o início do século XXI, desconsiderou a possibilidade de se publicar as partes vocais e instrumentais das composições editadas, apresentando apenas suas partituras. Transparece, nesse fato, um destino mais acadêmico que musical das edições, embora, paradoxalmente, os métodos de edição, até o final do século $X X$, tenham sido predominantemente práticos.

0 resultado dessa opção é que, apesar de estar disponivel a partitura impressa, é necessário re-copiar suas partes, manualmente ou eletronicamente, para tornar possivel sua execução, o que implica em custos e recursos, nem sempre disponiveis. Alguns editores distribuem informalmente as partes referentes às suas edições, mas essa possibilidade resolve apenas parcialmente a necessidade do material para os músicos. Partituras sem partes desestimulam sua inclusão no repertório de regentes e grupos musicais, às vezes produzindo o efeito oposto ao desejado pelos seus editores.

Tudo depende da finalidade da edição. Se a proposta é que a música seja executada publicamente, deixar de publicar as partes tornará esse objetivo cada vez mais difícil. Com o acúmulo de tarefas e com tempo cada vez mais escasso, esperar que os regentes ou grupos musicais sempre providenciem o material para seus músicos está se tornando inviável. Por outro lado, se a proposta for exclusivamente acadêmica, com uma edição assumidamente direcionada ao estudo musicológico, as partes podem ser desnecessárias. Mas é preciso que as implicações de cada opção estejam bem claras aos editores.

\subsection{0 - Divulgação em papel ou em meios eletrônicos}

Afora algumas edições facsimilares em meios eletrônicos, as demais edições brasileiras de música antiga, até inícios do século XXI, foram exclusivamente divulgadas em papel. Coube ao projeto Acervo da Música Brasileira / Restauração e Difusão de Partituras (Fundarq/Santa Rosa Bureau Cultural/Petrobras, 2002-2003) a primeira proposta de edição simultânea em papel e na internet. Essa iniciativa abriu a possibilidade de consulta das partituras em larga escala, sem a necessidade de produção de grande quantidade de exemplares impressos. E o resultado ilustra os objetivos dessa série: um ano após a conclusão do projeto não existia mais exemplares das partituras para venda, porém sua página na internet registrava mais de 10 mil consultas - número recorde para uma página brasileira dedicada à musicologia - a maior parte delas para download das partituras.

A partir disso surgiram outras edições e projetos editoriais que consideram a divulgação na internet, incluindo o projeto Patrimônio Arquivístico-Musical Mineiro, cujas partituras e partes (somente o primeiro tipo impresso em papel) serão divulgadas também na internet e em $\mathrm{Cd}$-Rom.

Se a proposta da edição é sua máxima divulgação, não é mais possivel atingir esse objetivo apenas pela impressão exclusiva em papel. A divulgação em $\mathrm{Cd}$-Rom ou pela internet, com ou sem a impressão paralela em papel, dá às edições uma circulação incomparavelmente maior do que a que se obtém apenas pelas edições em papel. Sua difusão internacional aumenta e sua reprodução e transmissão torna-se extremamente fácil.

0 grande problema, aqui, é que nem todas as editoras ou instituições financiadoras podem concordar em disponibilizar gratuitamente as obras na internet, sobretudo aquelas que pretendem um retorno financeiro oriundo da vendagem das edições. Mesmo assim, existe a possibilidade de edição em $\mathrm{Cd}$-Rom ou de acesso pago na internet, embora a tendência atual seja mesmo pelo acesso gratuito. Mas, como sempre, é preciso avaliar se o papel e os meios eletrônicos são necessários ou se apenas um deles é suficiente para a proposta da edição. A opção não pode ser feita apenas por modismo ou pela aceitação dos modelos em voga, mas principalmente pela consideração dos objetivos da edição. Se soubermos exatamente o que queremos ao se editar uma obra ou coletânea, escolher os parâmetros de edição será bem mais fácil.

\section{4 - Considerações finais}

0 desenvolvimento da atividade editorial no Brasil requer, dos editores e instituições envolvidas com esse tipo de atividade, um rompimento dos dualismos observados e uma flexibilização de suas propostas. As posições extremas produzem limitações nos resultados e nem sempre satisfazem as necessidades atuais, deixando de proporcionar o sempre desejado impacto positivo no meio musical e musicológico. Romper as dualidades significa deixar de defender um dos extremos como 
única possibilidade de atuação, praticando e estimulando as diversas propostas editoriais e, quando possivel e conveniente, adotando posições intermediárias.

Além das que foram anteriormente discutidas, chegamos à maior de todas as dualidades neste campo de trabalho: editar ou não editar? 0 dilema da prática da edição enquanto atividade acadêmica precisa ser resolvido: dedicar-se exclusivamente à edição é um extremo tão prejudicial quanto dedicar-se exclusivamente à reflexão, no caso dos musicólogos históricos. É fundamental voltarmos a considerar a edição musical como uma atividade importante da musicologia e darmos a ela um significado e uma aplicação não somente no meio acadêmico, como também em toda a sociedade. Nesse sentido, cito um fragmento do prefácio de Bernardo ILLARI (2008) ao primeiro volume da série Patrimônio Arquivístico-Musical Mineiro:

"[...] A edição de música antiga é uma arte em extinção, que chegou a ser quase sinônima à pesquisa musicológica, mas que, em um passado mais recente, acabou tornando-se marginalizada dentro da disciplina. Mas o fato de que as edições estão fora de moda não as torna menos necessárias. Da mesma forma, o descaso do jovem e impetuoso adepto da Nova Musicologia, cheio de seu De Certeau, Spivak, Bhabha, Derrida e Foucault, em nada contribui para o aperfeiçoamento da difícil empresa que é a edição musical. Editar música é fácil, pensam eles; trata-se de uma atividade mecânica e repetitiva, sem requerer muita interpretação. Apenas selecione as fontes, copie cada linha na partitura e, voilà, eis a peça terminada, pronta para ser executada. Quem vai querer se preocupar com uma tarefa tão banal?

[...] Agora, sem música editada, a execução, a apreciação e o estudo são simplesmente impossíveis. No âmbito acadêmico, qualquer interpretação só é viável a partir de boas edições. E só um ignorante seria capaz de alegar que já temos todas as edições de que precisamos. Vastos setores do imenso panorama da música escrita são desconhecidos a alguns ou a todos nós, relegados ao esquecimento em alguma biblioteca adormecida. É por isso que, olhando do Sul, não editar música é suicídio: ao não editarmos partituras antigas, ao não as resgatarmos do esquecimento, ao não as examinarmos à procura de pistas sobre quem as cultivou, estamos com isso aos poucos matando nossa memória - o que equivale a matar a nós mesmos. A crise da musicologia é um fenômeno do Norte. É preciso cautela quando lidamos com essa crise do nosso lado do continente."7

Consciente de que a edição musical é especialmente necessária na América Latina, em função de ainda estar minimamente conhecido e divulgado seu repertório histórico-musical, Illari critica a tendência latino-americana de abandonar a edição e outras tarefas associáveis à corrente positivista, para dedicar-se exclusivamente ao trabalho reflexivo, como preferem os adeptos da Nova Musicologia (KERMAN, 1985). No Brasil, como em qualquer outra parte da América Latina, adotar um desses extremos como atividade única é o pior que se pode fazer pelo patrimônio histórico-musical e pela própria musicologia. Temos que editá-lo, mas também temos que refletir sobre o significado que teve, tem e poderá ter.

Afinal, nossas edições destinam-se a ser vendidas, a circular entre músicos e musicólogos, a alimentar nossa vaidade ou a constar em nossos currículos? Precisamos trabalhar sozinhos, em equipes ou em "feudos"? Queremos ampla ou restrita divulgação de nosso trabalho, facilitando ou não sua utilização por parte dos interessados? Uma extensa pesquisa e reflexão, com o cotejamento de fontes, fará parte da nossa edição, ou preferimos um trabalho rápido de transcrição e correção dos problemas mais evidentes? 0 que é mais importante, afinal, a obra ou seu ineditismo? Nossas edições destinam-se a prover repertório aos músicos e ao público ou a esmiuçar uma questão editorial? $\mathrm{E}$, sobretudo, a que e a quem serve o nosso trabalho?

Perguntas como essas precisam ser feitas antes de começarmos a trabalhar, pois sem suas respostas navegaremos a esmo no campo da edição musical, sem rumo certo, ou seja, sem objetivo. Saber exatamente o que queremos e quais são as conseqüências de nossas opções é o ponto de partida para qualquer projeto editorial. Assumir os objetivos que nos movem equivale a deixamos de ser meros expectadores, para nos tornarmos agentes do nosso próprio trabalho. 


\section{Referências}

ANDRADE, Mário de. Modinhas imperiaes: ramilhete de 15 preciosas modinhas de salão brasileiras, do tempo do império, para canto e piano, seguidas por um delicado lundú para pianoforte, cuidadosamente escolhidas, prefaciadas, anotadas e dedicadas ao seu ilustre e genial amigo, o maestro Heitor Villa-Lobos. São Paulo: Casa Chiarato, 1930. 49p.

ARAÚJO, Damião Barbosa. Memento baiano para côro e orquestra: estudo introdutório, restauração e revisão de Jaime C. Diniz. Estudos Baianos, Salvador, Universidade Federal da Bahia, n.2. 1970. 30, 23p.

ARAÚJO, Mozart de. A modinha e o lundú no século XVIII: uma pesquisa histórica e bibliográfica. São Paulo: Ricordi, 1963. $159 \mathrm{p}$.

CASTRO LOBO, João de Deus de. Matinas do Natal (Invitatório): coro a quatro vozes mistas, violinos (I e II), violoncellos (I e II), flautas, trompas e c. baixo (II cello). Rio de Janeiro: FUNARTE / Instituto Nacional de Música / Lira Ceciliana, s.d. 10p. (Música Sacra Mineira, n.61)

COTTA, André Guerra (org.). Lobo de Mesquita no Museu da Música de Mariana: Homenagem a José Joaquim Emerico Lobo de Mesquita (1746?-1805) no bicentenário de seu falecimento. Mariana, Belo Horizonte: Fundação Cultural e Educacional da Arquidiocese de Mariana, 2005.

DUPRAT, Régis. Recitativo e Ária para soprano, violinos e baixo. Universitas, Universidade Federal da Bahia, n.8/9, p.291299, 1971, facsímiles (2f. inum.) e partitura (22p.).

; VOLPE, Maria Alice; TONI, Flávia Camargo. Recitativo e ária para José Mascarenhas. São Paulo: Editora da Universidade de São Paulo, 2000. 178p. (Coleção Uspiana - Brasil 500 Anos)

(org.). Música sacra paulista. São Paulo: Arte \&t Ciência; Marília: Editora Empresa Unimar, 1999. 308p.

FIGUEIREDO, Carlos Alberto. Editar José Maurício Nunes Garcia. Tese (Doutorado) - Centro de Letras e Artes da Uni-Rio. Rio de Janeiro, 2000. 2v.

GOMES, André da Silva. Missa a 8 vozes e instrumentos; descoberta e restauração Régis Duprat. Brasilia: Universidade de Brasilia, Instituto Central de Artes, Departamento de Música, 1966. 3p. inum., 151p.

GRIER, James. The Critical Editing of Music: History, Method, and Practice. Cambridge: Cambridge University Press, 1996. 266p.

ILLARI, Bernardo. Prefácio/Foreword. In: CASTAGNA, Paulo (coord.). José Joaquim Emerico Lobo de Mesquita. Belo Horizonte: Secretaria de Estado de Cultura de Minas Gerais, 2008. (Patrimônio Arquivístico-Musical Mineiro, v.1) (no prelo)

KERMAN, Joseph. Contemplating music: chalenges to musicology. Cambridge: Harvard University Press, 1985. 255p.

LANGE, Francisco Curt. Archivo de Música Religiosa de la "Capitania Geral das Minas Gerais" (Siglo XVIII), Brasil: Hallazgo, Restauración y Prólogo, Francisco Curt Lange. Tomo I. Mendoza: Departamento de Musicología, Universidad Nacional de Cuyo, 1951. 102p.

LIMA, Edilson de. As modinhas do Brasil. São Paulo: Editora da Universidade de São Paulo, 2001. 274p. (Coleção Estante USP - Brasil 500 Anos)

LOBO DE MESQUITA, José Joaquim Emerico. Quatro Tractus do Sábado Santo; coro mixto, órgão e violoncelo obrigado; descobrimento e restauração por Francisco Curt Lange (1964); nota introdutória de Jaime C. Diniz. Recife, Coro Guararape, 1979. vi, 15p.

. Tercio 1783: para solista[s], coro e orquestra de cordas; texto: Maria da Conceição Rezende Fonseca. Rio de Janeiro: FUNARTE / Instituto Nacional de Música / Projeto Memória Musical Brasileira, 1985. 66p.

MORAES, Geraldo Dutra de. Música barroca mineira; prefácio de Márcio Antônio da Fonseca e Silva. São Paulo: Conselho Regional de Farmácia do Estado de São Paulo: 1975. 64p.

OLIVEIRA, Manoel Dias de (atribuído a). Te Deum em ré maior; restauração e revisão de José Maria Neves. Belo Horizonte: Universidade Federal de Minas Gerais, Escola de Música, 1989. 64p. (Coleção Música Brasileira, v.1)

NEVES, José Maria (org.). Catálogo de obras: música sacra mineira. Rio de Janeiro: Funarte, 1997. 137p.

PALESTRINA, Giovanni Pierluigi da. Pierluigi da Palestrina's Werke. Leipzig: Breitkopf \& Härtel, c.1870-1907. 33v.

PINTO, Luís Álvares. Te Deum laudamus: restauração e revisão do padre J. C. Diniz. Recife: Depto. de Cultura da Secretaria de Educação e Cultura de Pernambuco, 1968.

SANTOS, Antonio Vieira dos. Cifras de música para saltério. Estudo e transcrições musicais: Rogério Budasz. Curitiba: Ed. da UFPR, 2002. 70, 112p.

SINZIG, Pedro. Modinhas brasileiras. Petrópolis, Vozes, 1921.112p.

SIQUEIRA, João Baptista. Modinhas do passado: investigações folclóricas e artísticas. Rio de Janeiro: Jornal do Brasil, 1956. $185 p$. 
Paulo Castagna é Graduado e mestre pela ECA/USP e Doutor pela FFLCH/USP. Foi bolsista do CNPq, da FUNARTE, da FAPESP e da VITAE, sendo atualmente Bolsista em Produtividade do CNPq. Vem produzindo partituras, livros e artigos na área de musicologia histórica, além de cursos, conferências, programas de rádio e televisão, também coordenando a pesquisa musicológica para a gravação de CDs. É professor e pesquisador do Instituto de Artes da UNESP desde 1994, atuando no Programa de Pós-Graduação em Música e coordenando o grupo de pesquisa "Musicologia Histórica Brasileira", cadastrado no CNPq. Coordenou a Equipe de Organização e Catalogação da Seção de Música do Arquivo da Cúria Metropolitana de São Paulo (1987-1999), a Equipe Musicológica do projeto Acervo da Música Brasileira / Restauração e Difusão de Partituras (Fundarq/Santa Rosa Bureau Cultural/Petrobras, Belo Horizonte - MG) e o projeto Patrimônio Arquivístico-Musical Mineiro (Secretaria de Estado da Cultura de Minas Gerais, 2007-2008), tendo sido tutor do Programa Especial de Treinamento (PET) do IA/UNESP (2000-2004). Participou de encontros de musicologia na América Latina, Europa e Estados Unidos e atuou na coordenação de mais de dez encontros internacionais de musicologia.

\section{Notas}

1 Não serão aqui consideradas as composições publicadas em vida pelos seus autores, como as Matinas do Natal de José Maria Xavier (1819-1887), impressas em Munique em 1885, ou o poema sinfônico Prométhée de Leopoldo Miguez (1850-1902), impresso em Leipzig em 1895 (embora hoje façam parte do repertório que interessa à musicologia histórica), mas tão somente as edições de obras compostas em tempos bastante anteriores ao momento de sua impressão, por autores já falecidos, fazendo recair sua autoridade apenas nas fontes remanescentes.

2 Cabe aqui um esclarecimento sobre a coleção Música Sacra Mineira. Inicialmente, essa série teve um caráter bastante fragmentário, imprimindo separadamente Invitatórios, Responsórios, Antifonas e Motetos que pertenciam às mesmas Novenas, Matinas, Setenários ou conjuntos de Motetos de Passos, sendo divulgada em partituras com letras grandes e tinta azulada, em dois formatos: $34 \times 26 \mathrm{~cm}$ e $50 \times 31 \mathrm{~cm}$. As instituições responsáveis pela edição eram Funarte, Instituto Nacional de Música e Lira Ceciliana (de Prados - MG) e cada obra possuía um número de identificação. Em um segundo momento, essas unidades musicais foram reunidas em torno de unidades cerimoniais cuja música era ou parecia ser do mesmo autor, e reimpressas em tamanho único, com tinta preta e uma nova capa, a partir de fac-símiles das edições anteriores. Houve uma pequena mudança nas instituições responsáveis pela edição, que passaram a ser apenas a Funarte e o Instituto Nacional de Música, através do Projeto Memória Musical Brasileira, porém foi criado um novo sistema de numeração e abandonado o antigo. José Maria NEVES (1997) considerou essas duas fases como integrantes da primeira edição da coleção Música Sacra Mineira, adotando a segunda numeração como definitiva e omitindo a primeira. 0 problema é que subsistem, em bibliotecas e coleções particulares, raros exemplares dessas duas fases da primeira edição, cuja dupla numeração confunde 0 consulente. Apesar da importância do trabalho de José Maria Neves, uma nova pesquisa sobre a coleção Música Sacra Mineira é bastante necessária, começando-se com uma tabela de equivalência entre os dois sistemas de numeração e, talvez, considerando-se as duas fases como duas distintas edições.

3 As partes vocais e instrumentais da série Acervo da Música Brasileira foram totalmente elaboradas em 2003 visando sua publicação na internet, mas a Fundarq não levou adiante a proposta e o material ficou restrito aos grupos que possuem contato direto com os editores. Até o momento essas partes têm sido distribuidas informalmente, circulando eletronicamente entre os interessados.

4 É importante lembrar que, apesar de ter havido um consenso entre os participantes do I Colóquio Brasileiro de Arquivologia e Edição Musical (Mariana, 18 a 20 de julho de 2003), nem todos os editores têm observado o item 25 das "Conclusões e Recomendações" desse evento, referente à citação das fontes utilizadas: "As edições musicais que atendam a propósitos musicológicos devem sempre indicar, com absoluta clareza, as fontes utilizadas, suas particularidades (título ou frontispício, copista e/ou proprietário, local, data, partes disponíveis) e sua localização atual (ou seja, o acervo no qual está preservada), atentando-se para o estudo crítico da relação entre as mesmas. Tais edições também devem explicitar as normas editoriais utilizadas nesse processo, evitando-se as decisões sem fundamentação teórica ou documental."

50 que obviamente não é admissivel é a cópia, sem alterações, de uma edição pré-existente e sua divulgação como se fosse o trabalho de outro editor. Isso não seria um trabalho editorial, mas apenas uma cópia, manual ou eletrônica, de uma edição anterior, sem a identificação de seu verdadeiro editor. Mesmo considerando-se a utilização dos recursos eletrônicos, não podemos confundir edição com editoração. Mas a reedição de uma obra, com a consulta de suas fontes manuscritas, especialmente quando envolve novas fontes, novas idéias e novos aspectos editoriais, é perfeitamente legítima, devendo ser estimulada como uma estratégia de renovação. A desconsideração da reedição, por outro lado, levaria à estagnação do conhecimento existente sobre o repertório antigo, sem contar o seu efetivo desconhecimento, na medida em que as antigas edições fossem se esgotando ou saindo de circulação.

6 "Editing early music is a dying art, one that once was almost coterminous with musicological research, only to be expelled from the core of the discipline in more recent times. That editions are out of fashion does not make them any less necessary. Similarly, the disdain of the young-andeager New Musicologist who exudes De Certeau, Spivak, Bhabha, Derrida, and Foucault through all of his or her pores does nothing to improve the difficult task of editing music. Editing music is easy, they believe; it is mechanical and repetitive, it does not involve much interpretation. Just pick up your sources, copy every line in your score, and there you have it, your finished piece, ready for performance. Who could ever care about such a simple chore?"

7 "Now, without edited music, performance, enjoyment and study are simply impossible. As to scholarship, interpretation is possible solely on the basis of good editions. And only a fool could claim that we have all the editions we need. Enormous sectors of the vast landscape of written music are unknown to most or all of us, consigned to oblivion in some dormant library. This is why the failure to edit music is suicidal when seen from the South: by not editing early scores, by not bringing them back to life, by not examining them in search of hints of the people who once cultivated them, we are slowly killing our memories--which amounts to killing ourselves. Musicology's crisis is a Northern phenomenon. We need to be careful in dealing with it on our side of the continent." 